\title{
Uma Perspectiva Generalizada da Escola Austríaca no que Diz Respeito à Economia e ao Humanismo
}

\author{
Fernando Chavarro Miranda* \\ Alexander Sellamén Garzón ${ }^{* *}$
}

\begin{abstract}
Resumo: $\mathrm{O}$ ensino da economia como ciência, nas diferentes instituições acadêmicas ao redor do mundo, caracteriza-se pela especialização da formação, bem como por incutir uma metodologia que inclui elementos e instrumentos oriundos da matemática, econometria, microeconomia e macroeconomia, entre outros campos. Relegam-se a um segundo plano os aspectos que não são tratados de maneira direta, tal como a dimensão ético-humanista que se encontra implícita em seu conteúdo. A Escola Austríaca de Economia apresentou avanços nesta direção e defende a inclusão, na formação dos economistas, de temas de interesse coletivo e humanista. Este trabalho pretende proporcionar uma perspectiva panorâmica da economia e do humanismo a partir dos fundamentos teóricos da Escola Austríaca, considerando o ser humano como fundamento de todo e qualquer estudo econômico.
\end{abstract}

Palavras-Chave: Praxiologia. Ética. Humanismo. Bem-comum.

\section{A Generalized Perspective of the Austrian School Regarding Economics and Humanism}

\begin{abstract}
The teaching of economics as a science, in several academic institutions around the world, has been characterized by the specialization of their training and the infusion of a methodology that includes elements and instruments from Mathematics, Econometrics, Microeconomics and Macroeconomics, among other fields. The areas that are not treated directly, as the ethical and humanistic aspects that lie implicit in its content, are relegated to a secondary place. The Austrian School of Economics presents advancements in this direction and defends the inclusion, in the formation of the economists, of subjects of collective and humanistic interest. This paper intends to offer a panoramic view of economics and humanism from the theoretical background of Austrian Economics, considering the human being as the foundation of every economic study.
\end{abstract}

Keywords: Praxeology. Ethics. Humanism. Common good.

Classificação JEL: A14, A2, B53.

\footnotetext{
* Fernando Chavarro Miranda é professor de economia na Universidad de Los Andes (Colômbia) e membro do Conselho Editorial do periódico MISES: Revista Interdisciplinar de Filosofia, Direito e Economia.

E-mail: fernando.chavarro@yahoo.es

** Alexander Sellamén Garzón é economista, professor da Facultad de Administración de Empresas da Universidad Santo Tomás (Colômbia) e membro do Centro de Pesquisas em Economia Social “Louis Joseph Lebret”.

E-mail: alexsellamen@gmail.com
} 


\section{I - Uma Visão Introdutória a Partir DO BEM-ESTAR}

O bem-estar comum, ou a busca pelas condições mais adequadas para a vida humana, é uma variável levada em consideração por todas as ideologias e pesquisas relacionadas ao estudo da teoria econômica. No discurso ético e político atual, ademais, o termo é um conceito retórico definido de diversas formas, que ocupa um lugar de destaque na filosofia política e social de vários autores ao longo do tempo. Constata-se que perdeu vigência, ou mesmo certa preponderância, quando se incluem correntes mais recentes, a partir da virada individualista da filosofia ocidental e com a preponderância do multiculturalismo ${ }^{1}$. Nas últimas décadas, voltou a adquirir relevância perante o exemplo histórico recente dos totalitarismos: isto é, devido à marginalização dos direitos humanos estabelecidos e à imposição de definições não aceitas do termo "bem- comum". Este termo, assim como as tentativas de implementá-lo na sociedade, tem sido relacionado, ao longo do tempo, a noções distintas. É pertinente realizar alguns esclarecimentos conceituais em ordem cronológica:

Na tradição clássica, ou aristotélico-tomista, a noção de bem-comum se relaciona ao bem das pessoas enquanto componentes de uma comunidade.

Tomás de Aquino (1225-1274) estabelece alguns aspectos adicionais à assim chamada tradição clássica: o bem-comum adquire seu significado no governo: "governar consiste em conduzir aquilo que é governado à finalidade que lhe é própria". Dessa maneira, a finalidade da comunidade não pode ser distinta do bem-estar humano.

Na modernidade, o conceito de bem-comum compreende diversos aspectos, di-

\footnotetext{
${ }^{1}$ ARGANDOÑNA, A. El Bien Común. Pamplona: IESE, Business School - Universidad de Navarra, 2011.
}

ferentes dos já apresentados na tradição clássica. Surgiram várias posições entre o liberalismo fundamentado no individualismo (no qual o bem-estar da sociedade fica em segundo plano diante do bem-estar da pessoa) e as posições coletivistas (nas quais a sociedade é uma entidade própria, dotada de um bem-estar coletivo que é distinto e superior ao dos cidadãos).

No século $X X$, considera-se que a pessoa forma parte de uma comunidade, assumindo subordinação na mesma. No entanto, a pessoa é muito mais do que um membro da comunidade, dado que possui uma dimensão transcendente. Assim, a sociedade deve ter, como fim, a pessoa humana.

Na segunda metade do século $X X$, a Doutrina Social da Igreja Católica catalogou, em sua ideologia, a concepção do bem-comum em torno do entendimento da pessoa como sujeito, raiz, princípio e fim de toda a vida social e de todas as instituições sociais.

Finalmente, na encíclica Caritas in Veritate, o papa Bento $\mathrm{XVI}^{2}$ estabelece que o bem-comum é um princípio ordenator da vida econômica e, em particular, das relações entre o mercado, o Estado e a sociedade civil $^{3}$.

Basicamente, tal como se pode apreciar, a concepção do termo "bem-comum" compreende uma discussão bastante antiga, na qual a época e as situações conjunturais são predominantes para infundir diversas acepções a esse termo. De qualquer modo, independentemente da época e da ideologia dominante, ou mesmo dos conceitos novos que surgem na busca de soluções e definições con-

2 BENTO XVI. Carta encíclica Caritas in Veritate. Disponível em: <http://w2.vatican.va/content/ benedict-xvi/pt/encyclicals/documents/hf_ben-xvi_ enc_20090629_caritas-in-veritate.html>.

${ }^{3}$ ARGANDOÑA. El Bien Común, p. 4. 
cretas para esta expressão, pode-se concluir que todas as características do termo se orientam para a busca do "bem-estar do homem", impondo o ser humano como objeto principal e central na busca da satisfação de suas necessidades.

De acordo com Carl Menger (1840-1921), o ser humano e a maneira como empreende suas decisões se constitui como a unidade adequada para a análise econômica universal, na qual se incluem aspectos de escolhas subjetivas ${ }^{4}$. É nesta situação que se pode estabelecer que todas as decisões são tomadas com respeito à satisfação do ser humano no que tange ao seu bem-estar. Daqui, a economia com visão humanista é uma alternativa fundamentada em aspectos teóricos que aposta, por intermédio de uma análise alternativa, no desenvolvimento "mais humano" das propostas econômicas dominantes, baseado em princípios tais como a solidariedade entre os povos, assim como o equilíbrio necessário entre a vida interior e sua expressão externa; trata-se de todo um pensamento econômico consolidado em torno do humanismo, que oferece propostas distintas para denunciar a decadência moral e social, um pensamento renovado acerca dos valores humanos essenciais e, ademais, que busca o estabelecimento de uma proposta renovada para a conduta pessoal no interior da sociedade: isto é, concentra-se na passagem de uma ética individual para uma ética geral.

Os aspectos teóricos infundidos são amplamente aceitos. Apesar disso, faz-se necessário implementar aspectos alternativos da ciência econômica para incutir esses elementos com mais profundidade. A Escola Austríaca de Economia é uma corrente de pensamento que pode contribuir, de maneira direta, para a formação de economistas dotados de um senso distinto do pensamento e da racionalidade, orientados para a busca da satisfação das necessidades humanas. Conforme mencionado nos parágrafos anteriores, a

\footnotetext{
${ }^{4}$ BOETTKE, P. J. Hacia una Robusta Antropología de la Economía: La Escuela Austríaca en 10 Principios. Argentina: Instituto Acton Argentina, 2010.
}

economia, enquanto ciência social, estudada a partir da praxiologia (termo próprio da Escola Austríaca), tem por objetivo o estudo da estrutura lógica da ação humana nos processos de tomada de decisões e se baseia em aspectos teóricos que, na análise corrente da conjuntura nacional, parecem estar em segundo plano. De qualquer maneira, levanta-se a problemática específica segundo a qual a economia se encontra em processo de "desumanização", no qual são implementadas, em maior medida, práticas e fundamentos teóricos das ciências exatas, deixando à margem, de maneira evidente, aspectos tais como "escolhas subjetivas", o "agir humano em condições de democracia e liberdade" e a "ação humana como princípio fundamental das dinâmicas econômicas". Na atualidade, concebe-se que o agir humano se encontra estigmatizado pela preponderância de métodos de análise que são próprios das ciências exatas, embora, desde seus primórdios, a economia, enquanto ciência, fundamenta-se no comportamento do ser humano.

\section{II - Uma Introdução ao Pensamento da Escola Austríaca}

Pode-se dizer que há um certo consenso entre especialistas na afirmação de que a Escola Austríaca de Economia nasceu nas últimas décadas do século XIX, mais especificamente em 1871, com o aparecimento do livro "Princípios de Economia Política", de Carl Menger $^{5}$, o único e verdadeiro fundador da Escola Austríaca ${ }^{6}$. Menger estabeleceu, em seu livro, as bases para as teorias do valor e dos preços, que constituem os aspectos mais essenciais da Escola Austríaca:

A preocupação intelectual de Menger foi o estabelecimento de uma conexão causal

${ }^{5}$ MENGER, Carl. Princípios de Economia Política. Rio de Janeiro: Abril, 1983.

6 PIÑA ORTIZ, Edgar. El Desarrollo Sustentable: Aportaciones de la Escuela Austríaca de Economía. Estudios Sociales, Vol. 13, No. 25 (2005): 142-161. 
entre os valores subjetivos subjacentes às decisões dos consumidores e os preços objetivos empregados nos cálculos dos empresários. Sua maior contribuição e a essência de sua "revolução" na ciência econômica foi a comprovação de que os preços não são nada além da manifestação objetiva de processos causais iniciados voluntariamente e direcionados para a satisfação de desejos humanos ${ }^{7}$.

Esta corrente de pensamento contribuiu para a formação e definição de toda uma revolução científica que conduziu ao marginalis$\mathrm{mo}^{8}$. A obra de Menger possibilita observar e tratar com detalhes o problema econômico do valor no que concerne à subjetividade, a qual, devido à sua característica mais evidente, assume como principal desafio a incerteza e os desequilíbrios derivados de um processo submetido à temporalidade, mas que também, graças ao funcionamento das instituições, é objeto de ajustes permanentes em sua coordenação?

Carl Menger e seu aluno e sucessor na Universidade de Viena, Eugen von Böhm-Bawerk (1851-1914) - quem desenvolveu as ideias de seu professor, a partir dos anos 1880, em edições sucessivas de sua obra intitulada "Capital e Juros"10 - fundamentaram suas análises nas avaliações, ações e escolhas dos indivíduos, e explicaram os aspectos do que hoje se conhece pelo nome de microeconomia (utilidade, preços, trocas, produção, salários, juros e capital) ${ }^{11}$. Em síntese, Menger lançou,

\footnotetext{
${ }^{7}$ Idem. Ibidem, p. 2.

${ }^{8}$ Para mais informações, ver: ESCARTIN GONZÁLEZ, Eduardo. Historia de Pensamiento Económico, Tema 23: El Marginalismo. Disponível em: <http://personal. us.es/escartin/Jevons_Marginalismo.pdf $>$.
}

${ }^{9} \mathrm{ROMERO}$, J. A. Escuela Austriaca: punto de encuentro entre tradición subjetivista y novedad marginalista. Guatemala: Eleuteria, 2008.

${ }^{10}$ BÖHM-BAWERK, Eugen von. Capital and Interest: A Critical History of Economical Theory. London: Macmillan and Co., 1890.

11 CUE MANCERA, A. La escuela austriaca de economía. Comercio Exterior, Vol. 50, No. 12 (Dic. 2000): 1099-1106. pela primeira vez, as bases subjetivas do valor econômico e explicou a teoria da utilidade marginal.

Ludwig von Mises (1881-1973), um dos representes mais destacados da Escola Austríaca, pertenceu à terceira geração de pensadores dessa corrente. Mises acrescentou, ao pensamento austríaco, o termo "praxiologia". Basicamente, de acordo com as colocações teóricas desta escola de pensamento, a economia se constitui como o estudo direto das ações entre seres humanos, compreendendo a estrutura lógica da ação humana nos processos de tomada de decisões. Assim, poder-se-ia mencionar que as considerações humanísticas proporcionam uma maneira melhor para compreender a ciência econômica e o desenvolvimento do ser humano em seu meio. Também apresentou uma defesa da sociedade civil como estrutura de mediação entre o indivíduo e o Estado. Ademais, estabeleceu que cada ator econômico se encontra orientado pelos seus propósitos e metas, criticando fortemente o positivismo, que considerava cientificamente desprovido de valor por tratar as pessoas como objetos inanimados que podem ser manipulados à vontade - uma postura que proporciona, às diversas classes sociais dominantes, um marco perfeito para justificarem suas atividades.

Alguns princípios gerais, derivados das colocações teóricas a respeito do ser humano de acordo com a Escola Austríaca, colocam o homem em situação de liberdade suficiente para a realização de escolhas livres - sendo o homem, com seus projetos e propósitos, o ponto de partida de toda a análise econômica. As ciências humanas se envolvem diretamente com os planos e objetivos dos indivíduos e esta orientação conduz ao estudo do processo de tomada de decisões. O objetivo das ciências humanas é a compreensão da característica básica do agir humano, a inteligibilidade. Assim, cai-se no erro recorrente de concluir que as ações humanas já se encontram constituídas e que, portanto, são previsíveis e passíveis de dedução a partir de um determinado padrão. Pode-se dizer que a Escola Austríaca 
estabelece marcos teóricos diretamente vinculados ao comportamento humano, o que impede, de uma forma ou de outra, a projeção e previsão das ações derivadas de acordo com um certo padrão de ações. Assim, a prioridade do comportamento do ser humano sobre os recursos analíticos que são próprios das ciências naturais e exatas é uma conclusão que deriva imediatamente das contribuições teóricas de Mises.

A busca do desenvolvimento com um sentido humano, sustentável, democrático, e equitativo encontra, nas ciências humanas, apoios indispensáveis na busca de soluções que se voltam para o bem-estar comum.

\section{III - Uma Visão Humanista a PARTIR da Escola Austríaca}

Nas reflexões a respeito do ensino da economia se observa um desvio em direção ao principal objeto de discussão da economia no contexto das ciências humanas. Para muitos teóricos, isso se entende como a compreensão do comportamento do ser humano na sociedade; uma posição que não é, de forma alguma, reducionista - como por exemplo a maximização do bem-estar diante de restrições orçamentárias, na qual se coloca em evidência o postulado da escassez dos recursos perante as necessidades ilimitadas do homem.

Esta abordagem simplista, baseada na otimização, é limitada. Afinal de contas, a evolução da história do pensamento econômico permite abstrair os elementos desenvolvidos na teoria objetiva do valor por Adam Smith (1723-1790), David Ricardo (1772-1823) e outros pensadores clássicos, a partir de uma ótica reducionista, para dar lugar à teoria introduzida pelos marginalistas a partir de 1871, que não surgiu como simples substituição, mas sim como construção que nasce dos vácuos do raciocínio econômico na história do pensamento científico e que, muito pelo contrário, permitiu ampliar seu escopo para entender não somente o "espírito econômico" das decisões humanas, mas também para fornecer à economia um valioso instrumento que possibilita contextualizar e entender qualquer tipo de ação humana.

Esse processo e instrumentalização é chamado, por Ludwig von Mises, de praxio$\operatorname{logia}^{12}$. Além de estudar a estrutura lógica da ação humana nos processos de tomada de decisões, a praxiologia também estuda as ações entre seres humanos, que realizam trocas em termos monetários, o que se denomina "cataláctica". Isto nos leva a mencionar que a economia não desconsidera os aspectos humanísticos. Muito pelo contrário, constitui-se em uma maneira melhor para compreendê-los.

Por outro lado, é de conhecimento geral que a corrente austríaca transita por um caminho distinto do de outras escolas do pensamento econômico, tais como a keynesiana, a monetarista, a teoria da escolha pública, a corrente historicista, o institucionalismo e o marxismo, principalmente devido à sua postura no que diz respeito à liberdade e à democracia. O desacordo é mais notável quanto se trata de políticas econômicas. Mesmo assim, austríacos, membros da escola de Chicago e os teóricos da escolha pública, por exemplo autores tais como Ludwig von Mises, Murray N. Rothbard (1926-1995), Milton Friedman (1912-2006) e James Buchanan (1919-2013), entre outros, juntam seus esforços para defender a economia de livre mercado contra seus detratores sociais-liberais e socialistas.

Está claro que, por mais que esses posicionamentos comuns sejam importantes, não deixam de ser triviais diante das diferenças fundamentais entre a Escola Austríaca de Economia, representada por autores tais como Mises e Rothbard, e as demais correntes. A diferença a partir da qual surgem todos os

\footnotetext{
${ }^{12}$ A praxiologia é a ciência que estuda a ação humana. A cataláctica é a parte da praxiologia que estuda as trocas entre os seres humanos, definidas em termos monetários. Ludwig von Mises divulgou o emprego destas expressões. Etimologicamente, praxiologia vem do grego antigo, como combinação de práxis (ação) e logos (ciência ou estudo).
} 
desacordos no nível da teoria econômica corresponde à pergunta fundamental que deve ser formulada por qualquer economista: qual é o objeto da economia e que tipo de proposições são os teoremas econômicos? A resposta de Mises é que a economia é a ciência da ação humana. Ademais, diz que suas afirmações e proposições não derivam da experiência e são, assim como as afirmações e proposições da lógica e da matemática, a priori. Ou seja, não estão sujeitas à verificação e falsificação com base na experiência e nos fatos; são logica e temporalmente anteriores a qualquer compreensão de fatos históricos; são, na verdade, pré-requisitos necessários para qualquer compreensão intelectual dos eventos da história ${ }^{13}$.

Assim, Mises fortalece o status da economia como ciência pura, uma ciência que tem mais em comum com a lógica aplicada do que com as ciências naturais empíricas. É por isto que Mises propõe o termo "praxiologia" para o ramo do conhecimento que se expressa na economia ${ }^{14}$.

Esta apreciação da economia como ciência a priori, uma ciência cujas proposições podem ser dotadas de justificação lógica rigorosa, é o que distingue os austríacos ou, mais precisamente, os misesianos, das demais correntes econômicas da atualidade. As outras correntes concebem a economia como ciênca empírica, assim como a física, que desenvolve hipóteses que exigem comprovações materialistas consequentes. Assim, as demais abordagens consideram a posição de Mises dogmáti-

13 MISES, Ludwig von. Human Action. Chicago: Henry Regnery, 1966. p. 32. A obra está disponível em português como: MISES, Ludwig von. Ação Humana: Um Tratado de Economia. São Paulo: Instituto Ludwig von Mises Brasil, 2010.

14 A obra metodológica de Mises se encontra principalmente em seus trabalhos: MISES, Ludwig von. Epistemological Problems of Economics. New York: New York University Press, 1981 ; MISES, Ludwig von. Theory and History. Washington, D.C.: Ludwig von Mises Institute, 1985 ; MISES, Ludwig von. The Ultimate Foundation of Economic Science. Kansas City, Kans.: Scheed Andrews and McMeel, 1978 ; e na primeira parte de MISES. Ação Humana: Um Tratado de Economia. ca e anticientifica, e rejeitam que os teoremas econômicos, a Lei da Utilidade Marginal, a Teoria dos Juros com base nas preferências temporais ou a Teoria Austríaca dos Ciclos Econômicos possam merecer o status de prova definitiva, dado que se revela logicamente contraditório negar sua validade.

A partir da perspectiva contemporânea, pode parecer surpreendente descobrir que Mises não considerava sua concepção como descontextualizada diante do ponto de vista preponderante no início do século XX. Mises não tentava prescrever o que os economistas deveriam fazer, em oposição ao que já estavam fazendo. Mais propriamente, considerava que suas contribuições, enquanto filósofo da economia, residiam em sistematizar e tornar explícito aquilo que a economia realmente era e como tinha sido concebida implicitamente por praticamente todos os que se diziam economistas.

Com efeito, ao realizar a apreciação da "ciência a priori", ao oferecer uma explicação sistemática daquilo que era conhecimento somente implícito e não proferido, Mises introduziu algumas distinções conceituais e terminológicas que, anteriormente, eram pouco claras e familiares, pelo menos para o mundo anglófono. Entretanto, suas posições a respeito do status da economia estavam, essencialmente, em total acordo com a posição ortodo$\mathrm{xa}$, naquele então, a respeito do assunto. Autores tais como Jean-Baptiste Say (1767-1832), Nassau William Senior (1790-1864) e John E. Cairnes (1823-1875), por exemplo, descreviam a economia de maneira muito semelhante à descrição proporcionada por Mises, embora não empregassem o termo "a priori".

Say, por exemplo, escreve:

Um tratado de Economia Política [...] confinar-se-á à enunciação de um punhado de princípios gerais, não demandando sequer o apoio de provas ou exemplos; porque estes não seriam mais do que a expressão daquilo que todos sabem, organizados de maneira conveniente para a sua compreensão, tanto no alcance total de cada um, quanto nas relações entre si. [...] a Economia Política [...] 
sempre que os princípios constituintes de seus fundamentos forem as deduções rigorosas que partem de fatos gerais inegáveis, descansa sobre uma base imóvel ${ }^{15}$.

\section{De acordo com Senior,}

[...] as premissas [do economista político] consistem de umas poucas proposições gerais, que resultam da observação, ou da consciência, e que praticamente não requerem prova, ou mesmo afirmação formal, pois quase todo homem, assim que as ouve, admite-as como familiares ao seu pensamento ou, ao menos, como parte de seu conhecimento prévio; e suas inferências são, da mesma forma, quase tão gerais e, caso tenha raciocinado corretamente, quase tão certas como suas premissas ${ }^{16}$.

Assim, os economistas devem estar "conscientes do fato de que esta ciência depende mais do raciocínio do que da observação, e sua principal dificuldade consiste não na constatação de seus fatos, mas sim no emprego de seus termos" ${ }^{17}$.

Por sua parte, John E. Cairnes ressalta que, enquanto

a humanidade não possui conhecimento direto dos princípios físicos básicos [...] o economista parte do conhecimento das primeiras causas. [...] $\mathrm{O}$ economista pode, portanto, ser considerado, desde o início de suas pesquisas, como alguém que já possui os princípios primários que governam os fenômenos que conformam seu tema de estudo, cujo descobrimento, no caso da pesquisa em física, constitui, para o pesquisador, sua tarefa mais árdua. [...] As conjecturas, na economia, encontram-se manifestadamente fora de lugar, dado que possuímos, em nossa consciência e no testemunho de nossos sentidos [...] prova direta e fácil daquilo que

${ }^{15}$ SAY, Jean-Baptiste. Treatise on Political Economy. New York: Augustus Kelley, 1964 [1880]. p. xx, xxvi.

${ }^{16}$ SENIOR, Nassau W. An Outline of the Science of Political Economy. New York: Augustus Kelly, 1965 [1836]. p. 2-3.

${ }^{17}$ Idem. Ibidem, p. 5. desejamos saber. Na Economia Política, de forma correspondente, uma hipótese nunca se utiliza como auxílio para o descobrimento de causas e de leis primárias ${ }^{18}$.

Finalmente, a caracterização epistemológica da Economia era considerada bastante ortodoxa e, certamente, não era idiossincrática, conforme entendia Mark Blaug (19272011) ${ }^{19}$, quando foi formulada explicitamente por Mises. O livro de Lionel Robbins (18981984), "Um Ensaio sobre a Natureza e a Importância da Ciência Econômica" ${ }^{20}$, que apareceu pela primeira vez em 1932, não é mais do que uma versão mais suave da descrição de Mises da ciência econômica como praxiologia. No entanto, foi respeitado pela profissão econômica como estrela guia em assuntos metodológicos por quase vinte anos.

Mises, contudo, não apenas observa a diferença entre a economia e as ciências empí-

18 CAIRNES, John E. The Character and Logical Method of Political Economy. New York: Augustus Kelly, 1965. p. 83, 87, 89-90, 95-96.

19 Blaug observa que, na juventude, era marxista, porém, com o passar do tempo, "de maneira lenta e extremamente cuidadosa cheguei a me dar conta que eles [os teóricos da Escola Austríaca] estavam certos e que todos os demais estávamos errados". Afirmou, ademais, ao avaliar a aplicação do paradigma neoclássico para justificar a possibilidade do cálculo econômico socialista, que se trata de uma coisa "tão ingênua, do ponto de vista administrativo, que chega a provocar o riso. Somente aqueles que acreditam no modelo de equilíbrio estático perfeitamente competitivo podem ter dado crédito a semelhante estupidez. Eu mesmo fui um dos que engoliram essa abordagem durante meus anos de estudante, na década de 1950, e agora não faço senão maravilhar-me diante de minha própria falta de percepção". Ver: BLAUG, Mark \& DE MARCHI, Neil (Eds.). Appraising Economic Theories. London: Edward Elgar, 1991. p. 508 ; e BLAUG, Mark. Review: From Marx to Mises: Post-Capitalist Society and the Challenge of Economic Calculation by David Ramsay Steele. The Economic Journal, Vol. 103, No. 421 (Nov. 1993): 1570-1571. Ver também: <http:// puntodevistaeconomico.wordpress.com/2011/11/24/ mark-blaug-1927-2011/>

20 ROBBINS, Lionel. Um Ensaio sobre a Natureza e a Importância da Ciência Econômica. São Paulo: Saraiva, 2012. 
ricas; também coloca em evidência a natureza desta diferença e explica como e por que uma disciplina singular, tal como a economia, que ensina a respeito da realidade sem precisar de observações, pode, em primeiro lugar, existir. Esta é a realização de Mises que dificilmente pode ser superestimada. Para poder entender melhor esta explicação, deve-se fazer uma incursão no campo da filosofia, ou, mais precisamente, no campo da filosofia do conhecimento, ou epistemologia. Em particular, deve-se examinar a epistemologia de Immanuel Kant (1724-1804), que encontra seu desenvolvimento mais completo na "Crítica da Razão Pura" ${ }^{21}$. As ideias de Mises a respeito da praxiologia se encontram sob clara influência kantiana, de maneira que Mises toma, de Kant, suas distinções conceituais e terminológicas, bem como algumas noções fundamentais a respeito da natureza do conhecimento humano; assim, é necessário levar em consideração alguns aspectos desenvolvidos por Kant.

Kant, no transcurso de sua crítica do empirismo clássico, em particular de David Hume (1711-1776), desenvolveu a ideia de que todas as nossas proposições podem ser classificadas de maneira dupla: por um lado, podem ser analíticas ou sintéticas; por outro lado, podem ser a priori ou a posteriori. O significado de tais distinções, em resumo, é o seguinte: as proposições são analíticas sempre que os meios da lógica formal forem suficientes para descobrir se são verdadeiras ou não; caso contrário, serão sintéticas. As proposições são a posteriori sempre que for necessário recorrer a observações para estabelecer, ou ao menos confirmar, sua veracidade. Quando as observações não são necessárias, as proposições são a priori. De acordo com Kant, a matemática e a geometria constituem exemplos de proposições sintéticas a priori. Sem embargo, também considera que uma proposição tal como o princípio geral de causalidade - ou seja, a afirmação de que existem causas ope-

${ }^{21}$ KANT, Immanuel. A Crítica da Razão Pura. Lisboa: Fundação Calouste Gulbenkian, 2001. rativas intemporais e que cada acontecimento se encontra imerso em uma rede de tais causas - é uma proposição sintética a priori.

Entretanto, Mises não está interessado, como Kant, na epistemologia em si mesma. Com seu reconhecimento de que a ação é a ponte entre a mente e a realidade externa, encontrou uma solução para o problema de como as proposições sintéticas a priori são possíveis e proporcionou noções extremamente importantes com respeito à fundamentação última de outras proposições epistemológicas que transcendem o Princípio de Causalidade, como por exemplo a Lei da Contradição nos fundamentos da lógica. Assim, abriu um caminho para a investigação filosófica que tem sido escassamente percorrido.

Mises não apenas reconhece que a epistemologia repousa indiretamente sobre nosso conhecimento reflexivo e que, portanto, pode alegar que estabelece algo a priori a respeito da realidade; também estabelece que a economia também o faz, e de maneira muito mais direta. Neste sentido, as proposições econômicas fluem diretamente a partir de nosso conhecimento da ação adquirida reflexivamente e o status destas proposições como afirmações verdadeiras a priori acerca de algo real decorrem de nossa compreensão, o que Mises chamou de "axioma da ação".

Este axioma, a proposição de que os seres humanos agem, cumpre com os requisitos de uma proposição sintética a priori verdadeira. Não se pode negar sua veracidade, dado que sua negação teria que ser classificada como uma ação e, dessa maneira, a verdade da afirmação não pode, literalmente, ser desarticulada. Ademais, o axioma tampouco deriva da observação - somente movimentos corporais podem ser observados, porém não algo como uma ação -, mas sim da compreensão reflexiva.

A grande observação de Mises foi que o raciocínio econômico encontra seu fundamento, mais precisamente, na compreensão da ação e de que o status da economia, como uma forma da lógica aplicada, decorre do axioma da ação humana como proposição 
sintética a priori. A lei das trocas, a lei da utilidade marginal decrescente, a lei ricardiana da associação, a lei dos controles de preços e a teoria quantitativa da moeda - exemplos de proposições econômicas - podem ser derivados logicamente a partir deste axioma. É por isso que se torna ridículo pensar, a respeito de tais proposições, que possam ser do mesmo tipo epistemológico das proposições das ciências naturais. Pensar desta maneira e, consequentemente, exigir experimentação para a sua comprovação, é como supor que devemos incorrer em um processo de busca dos fatos sem conhecer o resultado possível para estabelecer o fato de que somos, na realidade, seres que agem.

Finalmente, a praxiologia nos diz que todas as proposições econômicas que se afirmam como verdadeiras devem ser passíveis de dedução por intermédio da lógica formal do conhecimento verdadeiro e irrefutável, no que concerne ao significado da ação humana. Mais especificamente, todo raciocínio econômico se compõe do seguinte:

a) Uma compreensão das categorias da ação e o significado de que ocorrem mudanças em coisas tais como valorações, preferências, conhecimento, meios, custos, etc.

b) Uma descrição do mundo no qual as categorias da ação assumem um significado concreto, onde indivíduos concretos são identificados como atores com objetos específicos como seus meios para agir, com fins concretos identificados como valores e coisas concretas identificadas como custos. Tal descrição pode ser a do mundo de Robinson Crusoé, ou de um mundo com mais de um ator, no qual as relações interpressoais sejam possíveis: de um mundo de intercâmbios baseados no escambo, ou então de intercâmbios que empregam a moeda como meio comum.

Esta breve aproximação nos faz levantar os seguintes questionamentos:

1. Se, nas origens da economia, seus fundamentos estiveram marcados pela liberdade das forças do mercado (a mão invisível), sendo que tanto a ciência quanto estas forças são sustentadas pela ação humana, por que no final do século XX e início do século XXI se estigmatiza a ação humana e se valorizam mais os métodos e instrumentos das ciências exatas? Da mesma forma, deixa-se então de lado o objeto de estudo da economia, que é o comportamento do ser humano em seu ser contínuo e em suas interrelações com os demais atores da economia, para enfatizar o prognóstico e projeção da ação humana por intermédio dos instrumentos que são próprios das ciências exatas? Estamos diante de uma desumanização da própria essência da ciência econômica? Estamos transformando o homem econômico em uma máquina fácil de prever em suas ações, porém não com respeito ao que sente?

2. Se a economia é uma ciência social, por que deixamos de lado a riqueza do emprego da praxiologia e da cataláctica para, em seu lugar, permitir a passagem da desumanização da ciência econômica com o estabelecimento do Estado benfeitor e com o atrofiamento dos indivíduos em suas ações e em seu sentir, dentro e com a sociedade?

3. Se a moeda, em sua acepção mais depurada, é um acordo social, por que o Estado se outorga o direito de emissão? A existência de um Banco Central é algo essencial? Ou o Banco Central é apenas um instrumento dos Estados para desarticular o acordo social que sustenta a existência da moeda e, dessa maneira, sustentar a viabilidade de seu direito de emissão?

\section{IV - PERSPECTIVA A PARTIR DA ECONOMIA E DO Humanismo}

Algumas lateralidades morais pertinentes, que de alguma forma subjacem ao modo de convivência ocidental, podem ser revistas a partir de fatos históricos acidentais, como por exemplo a Revolução Industrial, a Revolução Francesa, a derrota dos absolutismos e os processos de expansão dos mercados que, atualmente, chamamos de globalização. 
A Escola Austríaca postula, a partir de Menger, que a análise econômica é suscetível de aplicação universal e que a unidade de análise apropriada é o ser humano com suas escolhas ${ }^{22}$. Antes de Menger, a tradição iluminista escocesa presta atenção às ordens sociais complexas, apresentando a economia por intermédio da metáfora da mão invisível, de modo que os preços e os mercados funcionam dentro do que se conhece como "ordens espontâneas". Além de ser uma ordem espontânea, o fenômeno social é uma ordem complexa.

Há diversos assuntos essenciais; o fenômeno social complexo compreende muitas variáveis. Na verdade, são tantas que não podem entrar, todas juntas, no conhecimento de qualquer ser humano. Assim, trata-se de uma ordem que não pode ser apreendida totalmente. Ademais, por ser uma ordem espontânea, é gerada a partir de uma multiplicidade de relações interpessoais entremeadas de várias formas, que podem ser analisadas a partir de vários pontos de vista. $\mathrm{O}$ fenômeno social se transforma em econômico, político, sociológico, jurídico ou moral, porque as pessoas se relacionam de todas essas maneiras. Esse acúmulo de relações, de intercâmbios, de formas de tratamento, relaciona-se absolutamente com o assunto complexo da natureza humana, que é o segundo assunto essencial. A respeito da complexidade da natureza humana, os homens são muito variados e variáveis.

A espécie humana é movida por forças opostas. Pode-se definir o homem como um ser que calcula, que segue regras, que imita, que deseja se destacar dos demais, que às vezes é cooperativo e dominante, que outras vezes é conservador e se amarra a certezas mínimas para estar seguro com relação às direções a seguir; que às vezes deseja aprender e inovar, mas que, no fundo, é paradoxal, porque os comportamentos das pessoas às vezes são antagônicos - dado que a própria natureza humana é multifacetada e complexa.

O mercado é uma destas ordens espontâneas, que surgem sem que ninguém os tenha proje-

${ }^{22}$ BOETTKE. Hacia una Robusta Antropología de la Economía: La Escuela Austríaca en 10 Principios. tado, como produto das relações entre os indivíduos que empreendem trocas voluntárias, que constituem os processos de descoberta, aprendizagem e informação. Nenhum indivíduo ou empresa pode saber, antecipadamente, como organizar de maneira ótima sua produção, quais produtos fabricar ou, inclusive, quais insumos deve empregar ${ }^{23}$.

Cabe, no entanto, questionar: por que existe um fenômeno social e por que há uma ordem complexa? Por que há um marco de convivência entre as pessoas e por que existe essa ordem cooperativa, ressaltada pelos austríacos, que caracteriza o Ocidente? No fundo, há dois problemas que sempre participaram da vida das pessoas. Os economistas dizem que um desses problemas é a escassez, pois os recursos não são suficientes para tudo o que desejamos satisfazer. O outro problema, enfatizado pelos estudiosos da ciência política, é que os conflitos existem e impedem a melhor convivência. Assim, as instituições são formas de organização social que se descobrem para tentar diminuir os conflitos e facilitar a convivência, por intermédio de regras que permitem a melhor cooperação e a maior produção de bens para que cada um possa satisfazer de forma mais adequada seus desejos e necessidades. O que está no fundo desse assunto é o questionamento acerca de como se diminui o conflito e como se combate a pobreza, ou como se gera riqueza, tal como seria colocado por Adam Smith em sua obra "A Riqueza das Nações". Trata-se de um desafio do fenômeno social como um todo e que não se resume a dizer como produzir mais, mas sim como produzir mais em uma ordem de mais convivência.

Os últimos duzentos anos de história econômica demonstram que, na luta contra a pobreza, temos nos saído bem, embora muitas pessoas ainda não tenham acesso ao mínimo para o sustento. Por volta do ano 1800, a população

${ }^{23}$ AMPUERO, D. Modelo de Crecimiento Económico Austriaco Basado en la Estructura del Capital. Universidad De San Francisco de Quito. 2016. Disponível em: $<$ http://www.usfq.edu.ec/publicaciones/polemika/Documents/polemika006/polemika006_005_articulo001. pdf $>$. 
mundial era de 800 milhões de pessoas. Atualmente, somos mais de 7 bilhões. Agora, as pessoas vivem em torno de 80 anos em vez de 35 ou 40. O mundo se tornou mais fácil, embora não nos demos conta disso. Há medicamentos que melhoram a qualidade de vida das pessoas e que resolvem problemas tais como a mortalidade infantil. Tudo isto indica que, em certo sentido, Thomas Malthus (1766-1834) estava errado e Adam Smith tinha razão.

Por que isto aconteceu? Por que sucederam estas coisas? Ocorreram devido às regras ou formas de agir, aos modos políticos, jurídi$\cos$, morais, sociais e econômicos de organização que, de um momento para outro, destacaram um conjunto de energias individuais, das pessoas que passaram a ser mais protagonistas da vida que thes correspondia viver. Obviamente, a criatividade e a inovação resultam desses espaços maiores para a liberdade. $O$ resto vem por acréscimo, para que exista uma ordem maior para a liberdade, complementar à ordem da economia e da eficiência. É uma questão inerente ao ser humano: quais são as atitudes que devem ser adotadas pelas pessoas que desfrutam de graus maiores de liberdade, ou que proporcionam mais liberdade.

Somente os indivíduos fazem escolhas. O homem, com seus planos e propósitos, é o princípio de toda análise econômica. Somente os indivíduos escolhem; as entidades coletivas não realizam escolhas. A principal tarefa da análise econômica é tornar o fenômeno econômico inteligível, apoiando-o nos propósitos e planos dos indivíduos. A tarefa secundária da economia consiste em indagar as consequências não pretendidas ou não previstas que podem surgir como resultado das escolhas individuais ${ }^{24}$.

É de vital importância abordar as relações interpessoais no fenômeno social e tratar das questões e perspectivas que facilitam as relações de cooperação. Há que avaliar este desafio com atenção, bem como o compromisso ético necessário para que este fenômeno não se decomponha. Não é evidente que nosso modo de vida

${ }^{24}$ BOETTKE. Hacia una Robusta Antropología de la Economía: La Escuela Austríaca en 10 Principios. e nossos valores atuais durarão para sempre. Estes valores devem ser defendidos com muito compromisso ético. Não está claro que o estado de bem-estar dos últimos duzentos anos perdurará.

Há, ainda, uma série de questões antropológicas: as pessoas que sustentam as ordens que apresentam os maiores graus de liberdade são pessimistas a respeito da natureza humana.

As visões românticas e idealistas de uma sociedade primitiva em harmonia com a nature$\mathrm{za}$, alheia à tecnologia e às relações de troca no mercado, não são congruentes com a realidade de nossa época ${ }^{25}$.

O idealismo tem uma visão muito pessimista acerca do homem porque reconhece que o ser humano é dotado de capacidades muito limitadas. Precisamos dormir várias horas por dia, as energias se esgotam, nosso tempo de vida é finito, nossa capacidade de compreender e entender não é tão grande. Entretanto, a visão da ordem social é muito otimista, dado que, em uma ordem de cooperação, esses seres humanos limitados e pessimistas conseguiram se relacionar ou misturar de modo sinérgico. Embora os indivíduos isolados não sejam capazes de atingir grandes resultados, os resultados obtidos pelo grupo são melhores. À medida que a ordem social se torna mais extensa, ela se divide e as pessoas se especializam mais. Rapidamente, começamos a desfrutar das vantagens que decorrem do que os outros sabem fazer. Assim, acreditamos que as ordens de cooperação geram muito bem-estar social, porém uma ou duas pessoas isoladas, desprovidas de relações em uma ordem social mais ampla, dificilmente conseguem chegar muito longe.

Há também questões sociológicas: quanto conhecimento pode ser abarcado por uma pessoa e quanta sabedoria pode ter. Diferentemente dos animais, o ser humano é dotado de racionalidade e da capacidade de apreender o que acontece em seu entorno, de ensimesmar-se, de fazer os próprios planos, de tentar transformar

${ }^{25}$ PIÑA ORTIZ. El Desarrollo Sustentable: Aportaciones de la Escuela Austríaca de Economía. 
um pouco o seu ambiente. Podemos aprender dialogando com os demais, ou então a partir de nossas experiências. Os mais inteligentes aprendem a partir das experiências dos outros. No fundo, contudo, o processo de aprendizagem também é uma ordem espontânea que brota das contribuições de diversos indivíduos. A atitude correspondente não é de dogmatismo ou de soberba, mas sim de humildade e de atenção ao que podemos compartilhar para aprender e melhorar. Conforme diziam os grandes autores Hayek e Karl Popper (1902-1994), é importante dialogar e colocar sob um olhar crítico aquilo que conversamos, dado que não somos os donos da verdade.

A terceira questão, relacionada com as pessoas que, no fundo, entendem o fenômeno social e exigem um maior grau de liberdade, é psicológica. Afinal de contas, para que desejamos mais liberdade? Uma resposta é: para concretizar os projetos de felicidade de cada um sem prejudicar os demais. Entretanto, a questão psicológica é muito importante, porque o ser humano, que é um ser racional, também é um ser que sonha, que tem a capacidade de idealizar. Os que se animam a sonhar com mais intensidade constroem propósitos na vida. Para realizá-los, contudo, a liberdade se faz necessária.

Há uma grande distância entre o modo praticamente tribal de cooperação, dos grupos pequenos, das sociedades mais fechadas e feudais, e a sociedade atual, na qual a cooperação institucional é a base que possibilita a defesa contra os ataques externos ou para obter os alimentos que permitem a subsistência do grupo. Hayek explica bem as questões tribais relacionadas à sobrevivência, já que não é própria do indivíduo, mas sim do grupo ${ }^{26}$. Assim, é viável pensar que, nesses âmbitos, os valores dominantes eram a lealdade e a solidariedade, pois havia um único objetivo social - a sobrevivência do grupo. Para lograr esse objetivo, cada indi-

\footnotetext{
${ }^{26}$ HERNÁNDEZ, W. Origen de las normas del recto actuar y de las instituciones en Hayek. Eleutheria (1990). Disponível em: <http://www.eleutheria.ufm. edu/Articulos/060921_Origen_de_las_normas_del_ recto_actuar_en_Hayek_htm>.
}

víduo precisava ocupar um espaço bem definido, dentro de estruturas hierárquicas mais rígidas.

Posteriormente, com a modernidade e a expansão do comércio, esses pequenos grupos de pessoas começaram a estabelecer relações com indivíduos que não são parentes próximos. As relações se tornaram mais impessoais, o mundo ficou mais extenso e a sociedade se tornou mais aberta. Neste ponto, a sociedade começou a demandar o reconhecimento da propriedade privada e da divisão do trabalho para que cada um pudesse desempenhar de maneira adequada seu papel na expansão das relações comerciais e profissionais.

Com a globalização, as mudanças nas regras se intensificam ainda mais e se tornam mais universais. Os direitos humanos, a abolição da escravidão e a inserção da mulher na vida política e pública assumem, agora, o caráter de normas para a promoção da igualdade. As relações entre os indivíduos se tornaram ainda mais horizontais.

Esta mudança sociológica compreende diversos desafios morais, porque já não se fala mais a respeito da moralidade nas relações humanas mais próximas, com amigos e familiares, mas sim do respeito para com pessoas estranhas que influenciam nosso modo de vida. É aqui que o amor, a lealdade e a fraternidade passam a dar lugar ao respeito, à justiça e à tolerância, isto é, os valores que imperam na sociedade se tornaram mais impessoais. Passamos a aprender com pessoas que vivem de modos distintos do nosso.

A ordem social mais aberta nos coloca diante de um desafio: cada um precisa renunciar à sua concepção como centro do universo e passar a se entender como parte de um grupo. A configuração social passou a ser mais transversal e começamos a pensar não só por nós mesmos, mas também pelos demais. Talvez esta seja a mudança mais importante, porque representa nossa saída dos instintos naturais do egocentrismo para a socialização com os outros. Com a difusão das normas, que se tornaram mais comuns, a reciprocidade passou a ser um fator cru- 
cial para entender nossos comportamentos e decisões.

De acordo com Mises, as trocas e a especialização, juntamente com a divisão do trabalho, permitem que possamos desenvolver o melhor de cada um a serviço dos demais no ambiente do mercado. Afinal de contas, para satisfazer aos consumidores, é necessário apresentar produtos sedutores ${ }^{27}$. Assim, cada um pode desfrutar das qualidades ou virtudes dos demais. A civilização nos possibilita aproveitar os esforços de todos, o que explica o sucesso de nossa vida atual. Em um ambiente de liberdade e em uma ordem baseada nas trocas, cada um tem acesso ao que os demais produzem.

Em outras palavras, cada ser humano, por intermédio de sua especialização, cria uma ordem de convivência e de comércio do conhecimento que resulta no florescimento econômico. Para que isto funcione, obviamente, as regras de convivência devem ser justas e as pessoas devem cultivar o respeito para com os demais. Por intermédio de negociações e conciliações, a cataláctica se expressa como uma troca que possibilita transferir bem-estar entre os indivíduos.

\section{$\mathrm{V}-$ ConClusões}

O que podemos aprender com esta análise? A resposta mais geral poderia ser que criamos leis universais que todos adaptamos e aceitamos em nossas vidas, com o propósito de melhorar a convivência. Há duas maneiras de abordar o problema do surgimento dessas normas. A primeira é pensar que as regras surgem espontaneamente, por tentativa e erro, e que os modos de comportamento dos indivíduos se adaptam no transcurso do tempo, até constituírem rotinas, tendências e modos de conduta previsíveis. Sob esta perspectiva, podemos entender as regras como

27 ROTHBARD, Murray N. Libertad, desigualdad, primitivismo y división del trabajo. Instituto Mises Hispano, 2012. Disponível em: <http://www. miseshispano.org/2012/04/libertad-desigualdadprimitivismo-y-division-del-trabajo/>. soluções institucionais. A segunda maneira é acreditar que essas regras resultam de um processo evolutivo do ser humano diante de suas necessidades de sobrevivência em um mundo cada vez mais civilizado.

A moeda, a moral e a linguagem são exemplos de regras que emergiram evolutivamente. Há situações, contudo, tais como o dilema dos prisioneiros na teoria dos jogos ou os dilemas hobbesianos na política, que nos obrigam a pensar em como responder às situações que indicam que o maior benefício, no curto prazo, é obtido mediante o recurso a meios não-cooperativos, tais como a trapaça ou a traição. Diante disso, torna-se necessário criar incentivos que direcionem os indivíduos para longe do comportamento de não-cooperação. Daí a criação de códigos e normas de conduta reunidas em planos constitucionais.

Entretanto, uma consequência possível é a geração de um mal público a partir das legislações positivas - por exemplo, por intermédio da corrupção e de distorções na relação entre o público e o privado. Quando os indivíduos se veem em uma ordem social injusta, a economia se deteriora, a criatividade tende a desaparecer e a convivência é prejudicada.

A moralidade, portanto, compreende fenômenos de interação entre as pessoas, possibilitando a descoberta de nossos próprios sentimentos morais. A análise econômica, que busca elucidar como as pessoas se comportam e tomam decisões, não se baseia apenas nas aplicações do cálculo racional - tal como enfatizado pelas vertentes mais ortodoxas da teoria econômica ${ }^{28}-$, mas também na percepção e orientação desses sentimentos morais. cos

28 RAVIER, A. Punto de Vista Económico. 16 fev. 2011. Disponível em: <https://puntodevistaeconomico. wordpress.com/2011/02/16/el-enfoque-austriacoy-el-enfoque-neoclasico-\%C2\%BFson-sustitutos-ocomplementarios/>. 